\title{
Deformation response of EPS foam under combined compression-shear loading. Part I: Experimental design and quasi-static tests
}

\author{
Chen Ling ${ }^{\mathrm{a}}$, Jan Ivens ${ }^{\mathrm{b}}$, Philip Cardiff ${ }^{\mathrm{a}}$, Michael D. Gilchrist ${ }^{\mathrm{a}, *}$ \\ a School of Mechanical \& Materials Engineering, University College Dublin, Dublin, Ireland \\ ${ }^{\mathrm{b}}$ Department of Materials Engineering, KU Leuven, J. De Nayerlaan 5, B-2860 Sint-Katelijne-Waver, Belgium
}

\section{A R T I C L E I N F O}

\section{Keywords:}

EPS foam

Combined compression-shear loading

Quasi-static

\begin{abstract}
A B S T R A C T
Expanded Polystyrene (EPS) foam material is widely used as an energy absorption engineering material. Its compression behaviour, both quasi-statically and dynamically, has been studied widely. However, its mechanical behaviour under combined compression-shear loading is poorly understood due to the difficulty of performing such tests. A novel test rig is presented to perform combined compression-shear loading tests in quasi-static and high strain rate dynamic conditions. Different densities of EPS foam were tested with this apparatus using a universal testing machine and a drop tower. The compressive and shear stress and strain curves were obtained and compared with the mechanical behaviour of EPS foam under pure compression. This showed that the shear deformation of EPS foam under combined compression-shear loading tends to lower the compressive stress at yield of the foam up to $40 \%$ compared with pure compression, depending on the density of the foam. A companion Part II paper will separately present and discuss the experimental results of the high strain rate dynamic tests of EPS foam under combined compression-shear loading.
\end{abstract}

\section{Introduction}

Expanded Polystyrene (EPS) foam is a cellular material used widely for energy absorption and thermal insulation applications, such as packaging $[1,2]$, as a structural core material $[3,4]$, for geofoam products [5-7], and as helmet liners [8-12]. Due to its light weight, low cost, easy manufacturability and, most importantly, good energy absorption, it has long been used as an engineering material in diverse applications. Modern cycling and sports helmets have been made using EPS foam as energy absorption liners for decades, whilst EPS geofoam was first used in Oslo in 1972 to address the settlement of bridges [13]. Much work has been done to investigate the mechanical behaviour of EPS foam material. Its compression behaviour, both at static and dynamic strain rates, has been studied widely $[5,6,14,15]$, but less so under the action of tensile, shear or more complex loading situations, such as combined compression/tension with shear behaviour. However, under many applications, the EPS foam is not subjected to pure compression. Most real loading cases involve the deformation of EPS foam due to a combination of compression and shear. Thus, it is very important to investigate the mechanical behaviour of EPS foam material under combined compression-shear loading conditions in order to better characterize and obtain its mechanical performance for corresponding applications.

There is extensive literature on the mechanical behaviour of EPS foam. Ashby et al. [16] studied the structure and mechanical proper- ties of EPS as a subset of cellular solids and found that the mechanical properties (elastic, plastic, creep and fracture) of foam are related to the cell wall material properties and geometry. Chen et al. [17] further studied the effect of cell size and wall thickness variations on the stiffness of closed-cell foams, and found that the Young's modulus and shear modulus decreased with increasing cell size and cell wall thickness; expressions incorporating cell size and cell wall thickness variations were formulated to predict the stiffness of closed-cell foams. Mihlayanlar et al. [18] studied the effect of production process parameters and density of EPS on its mechanical properties and thermal conductivity and found that the foam density seems to be the dominant controlling variable regarding the mechanical properties of EPS foam. The effect of production process parameters on the properties did not exceed $10 \%$, according to their study. Song et al. [19] investigated the strain-rate effects of EPS from 0.001 to $950 / \mathrm{s}$ by using a hydraulically driven test machine and modified SHPB dynamic testing system: the collapse stress and elastic modulus were found to increase with strain rate, and a rate-dependent material model was proposed to describe the experimental results. Ouellet et al. [20] studied the compressive response of EPS at quasi-static, medium and high strain rate conditions and found that the rate effects become more pronounced at rates above approximately 1000/s. Koohbor et al. [21] investigated the dynamic stress-strain response of rigid closed-cell polymeric foams by quantifying their deformation response with high speed stereo-photography and 3D digital image correlation.

\footnotetext{
* Corresponding author.

E-mail address: michael.gilchrist@ucd.ie (M.D. Gilchrist).
} 


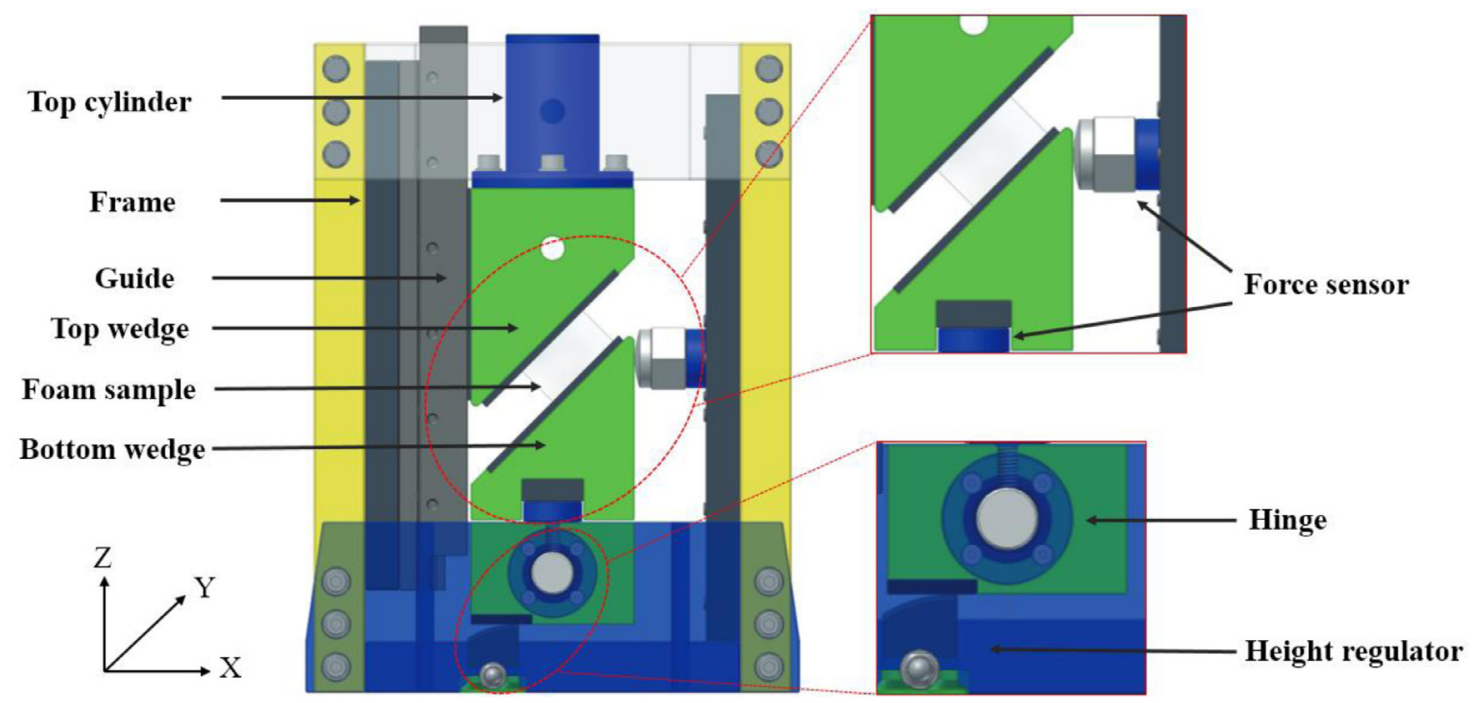

Fig. 1. The fixture designed for combined compression-shear loading on EPS foam at $45^{\circ}$ loading angle.

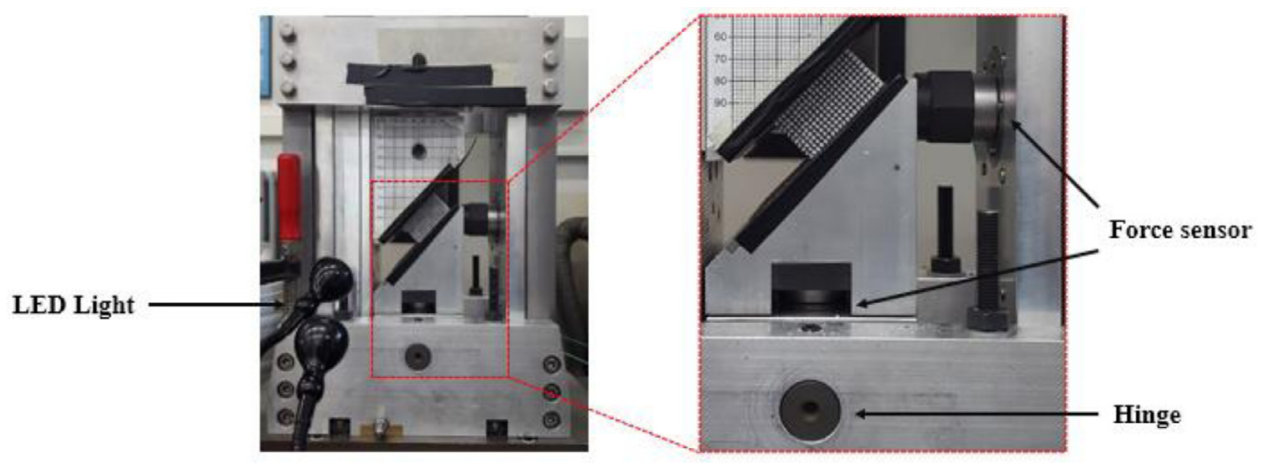

Fig. 2. The setup of the test rig.

Despite the many studies on the mechanical behaviour of EPS foam, most have been based on pure compression tests, in which strain rate varied from quasi-static to high strain rate. Very few studies have considered the combined effects of compression-shear loading on foam material, due to the difficulties of performing such experiments, since custom designed fixtures are required to realize such loading. Among the few studies, Hou et al. [22,23] developed a test rig to study the impact behaviour of honeycombs under combined compression and shear loading, which was based on a modified SHPB with bevel end cylindrical bars to introduce the combined compression-shear loading. Tounsi et al. [24] investigated the possibility of applying a reduced numerical model to simulate the influence of in-plane orientation and the loading angles on the crush behaviour of honeycombs under mixed shear-compression loading. Dorogoy et al. [25] characterized the dynamic large strain behaviour of polycrystalline tantalum by using a modified shear compression specimen (SCS) on a split Hopkinson pressure bar. Their results indicate that the dynamic failure behaviour of the material at high strain rates in shear-tension is markedly different from that in shearcompression. Vogler et al. [26,27] developed a biaxial testing facility to study the failure of composite fibre and the inelastic behaviour of an AS4/PEEK composite under combined compression and shear. Mosleh et al. [28] studied the effect of the anisotropy of polymer foam on energy absorption during combined shear-compression loading by using two independent displacement actuators that were aligned biaxially and controlled independently to realize combined compression-shear loading, yet the strain rate was limited to quasi-static load conditions.

In the work by Hou et al. [22], it was not possible to obtain the compressive and shear force components applied to the honeycombs

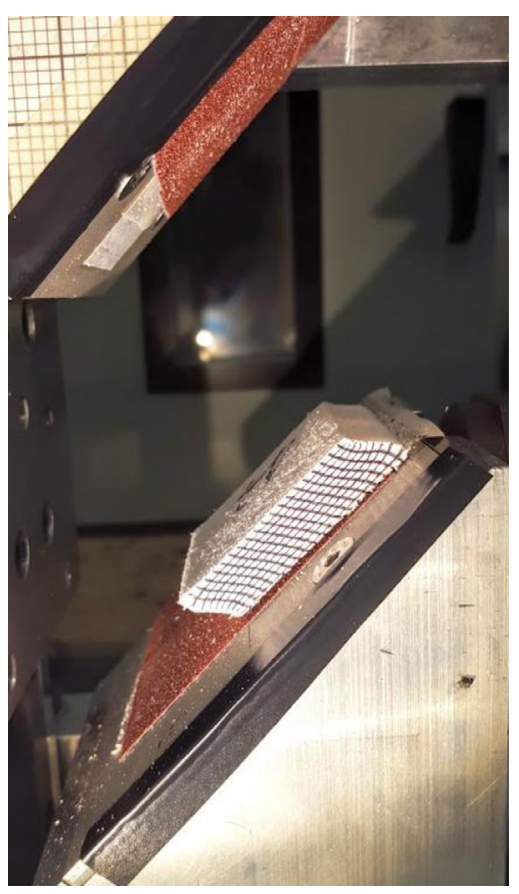

Fig. 3. The placement of foam sample. 


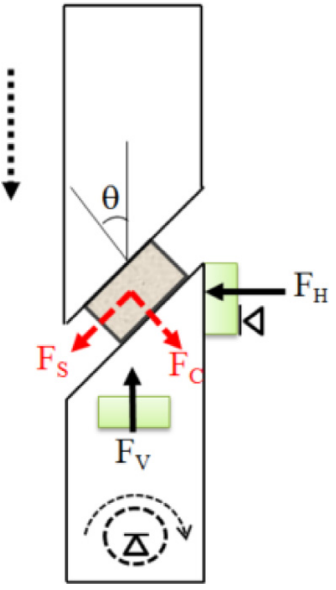

Fig. 4. The scheme of the force measurement fixture, which includes a frictionless hinge joint on the bottom platen.

from their loading device due to measurement limitations and it was only possible to obtain an overall pressure-crush relationship from their experiments. To solve this problem, in the present study, we have developed a new test rig to realise combined compression-shear loading tests, from which the compressive and shear force component of the EPS foam can be obtained independently by using two load cells in the test rig. Quasi-static tests were performed by integrating this rig with an Instron machine. The experimental setup will be described in detail in Section 2. The principles to measure the compression and shear behaviour of foam material will be described in Section 3. The experimental results on four different densities of EPS foam will be presented in Section 4. The conclusions will be summarized in Section 5 .

\section{Experimental setup}

An universal test machine typically uses a flat loading plate for pure compression tests on bulk materials. In order to perform combined compression-shear loading on foam material, a special apparatus was designed to hold samples and measure force. The fixture, as shown in Fig. 1, was designed to apply combined compression-shear loading at a $45^{\circ}$ loading angle. To demonstrate the experimental approach for other loading angles, a similar loading platen was designed to apply load at $60^{\circ}$ loading angles although the present paper concentrates solely on the use of and results from the $45^{\circ}$ fixture (Fig. 2).
In this fixture, the combined compression and shear loading condition was realized by introducing two inclined $45^{\circ}$ wedges to hold the sample: the top loading wedge was restrained to Z-axis translation only, while the bottom wedge was hinged to the bottom frame, thereby allowing rotation about the Y-axis only. However, a force sensor connected to a hemispherical contact surface cylinder was set at the right side of the bottom wedge to prevent any free rotation of the bottom wedge. Simultaneously, the corresponding horizontal force was measured by the force sensor. The components of the frame are made from stainless steel and aluminium and are fixed together by bolts to increase the stiffness and robustness of the system. The top wedge, fixed with a vertical guide on the left side allowing only motion in the Z-direction, is used to apply the loading. The vertical guide is fixed on the left side of the frame with screws, ensuring that all other motions of the top wedge block are prevented. A cylinder with a flat top surface is connected to the top wedge to apply the load or displacement, for instance by the crosshead of the Instron machine, thus applying a load or displacement control to the EPS foam sample. A height regulator is set under the left bottom side of the fixed block, making it possible to regulate the location of the block subtly, thereby ensuring good contact between the bottom wedge and horizontal force sensor at the beginning of the test (Fig. 3).

Two force sensors are used to measure the forces during the loading: A Kistler 1-component force sensor (Type 9041A with measuring range $0-90 \mathrm{kN}$, sensitivity $\approx-4.3 \mathrm{pC} / \mathrm{N}$ ), mounted inside the bottom wedge, is used to measure the vertical force during the test. As the bottom wedge has the freedom to rotate around the Y-axis once the vertical load is applied, and as this rotation is constrained by a similar Kistler force sensor, which is fixed horizontally to the right side of the frame and hemispherical point contact with the right side of the bottom wedge, this means that a horizontal reaction force is created and measured by this force sensor during the test. The contact area is specially designed, as shown in Fig. 1, in the form of a hemispherical shape to ensure that only horizontal force is transmitted to the Kistler load cell. The vertical loading is transmitted to the EPS foam through the guide by the crosshead of the Instron machine. As the guide is practically frictionless, the friction losses from the guide during testing can be ignored; this was verified separately by comparing the vertical load value from the Kistler load cell and the Instron load cell: only an insignificant difference was found. The compressive and shear forces on the foam samples can then be obtained based on the horizontal and vertical forces measured from the Kistler force sensors. This will be discussed in detail in Section 3.1.

The foam sample is glued to a thin plate by a strong adhesive Tesa tape, which is then affixed to the bottom wedge by screws. $3 \mathrm{M}$ coarse sandpaper (grain size P80) is used on the wedges to avoid slippage of the

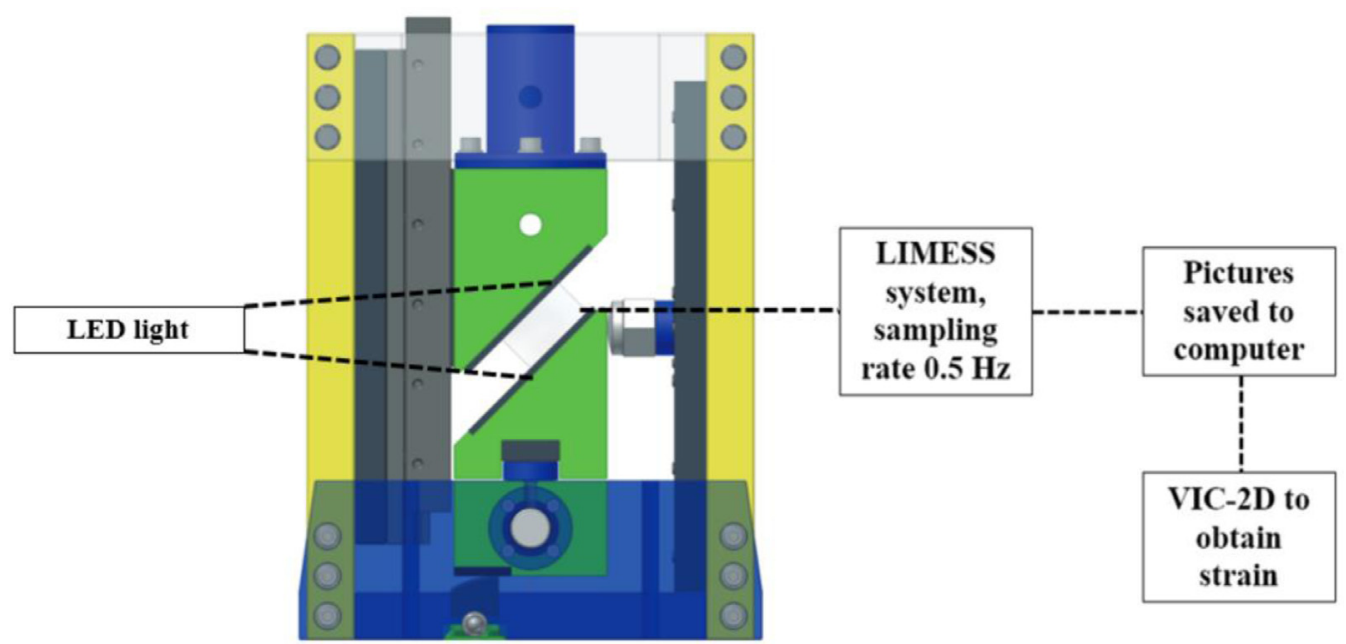

Fig. 5. strain measurement schematic principle. 

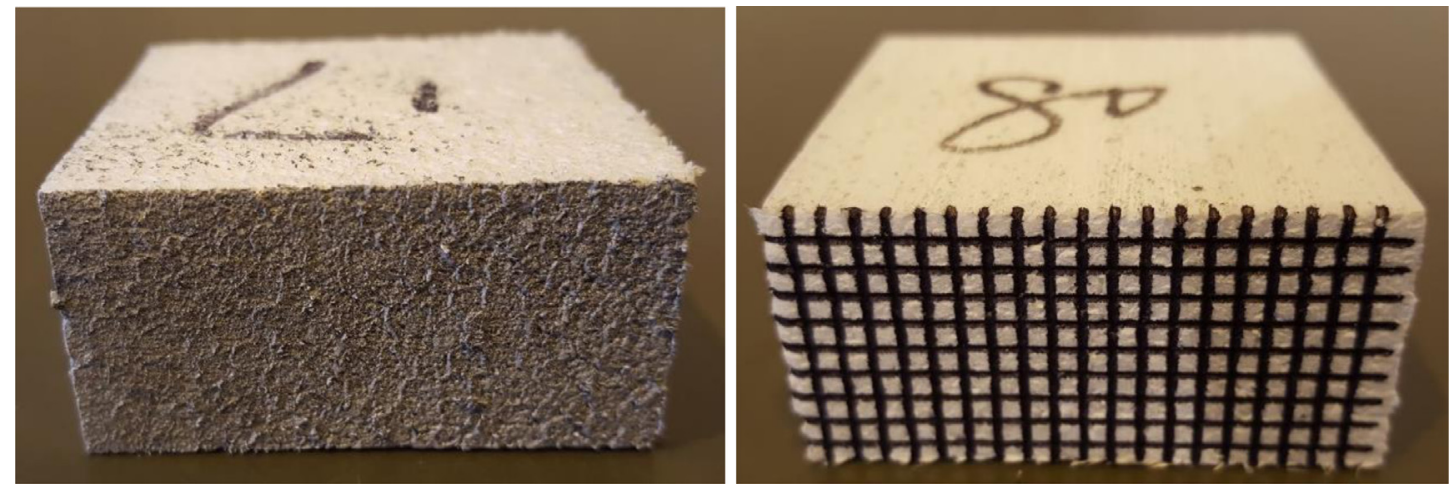

Fig. 6. Paint spray speckle and grid pattern on foam surfaces.

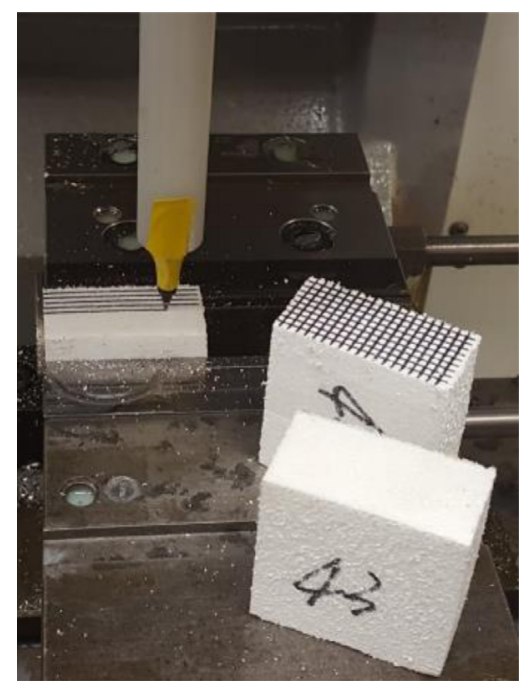

Fig. 7. CNC machine marking grids on foam samples. foam samples during the test. Laser engraved markings on the thin plate helped to ensure the consistency of replacing new samples and performing all the tests easily and repeatedly at the same position. The location of the marker was specially designed to ensure that the axis of the vertical force sensor passes through the centre point of the foam sample. Two LED cold light illuminators were used to shed light on the foam samples, thereby improving the contrast of the real-time images captured by the Digital Image Correlation system LIMESS [29] sufficiently for strain measurement purposes.

\section{Measurement principles}

\subsection{Force measurement}

It is difficult to measure the compression and shear forces directly from the combined compression and shear tests. For this reason, in our setup, these two forces were not measured directly during testing. During an experiment, when the crosshead of the test machine pushes down the top wedge, load is transferred to the EPS foam, and thence to the bottom wedge. However, the vertical movement of the bottom wedge is restricted since its hinged fixation only allows rotation around the

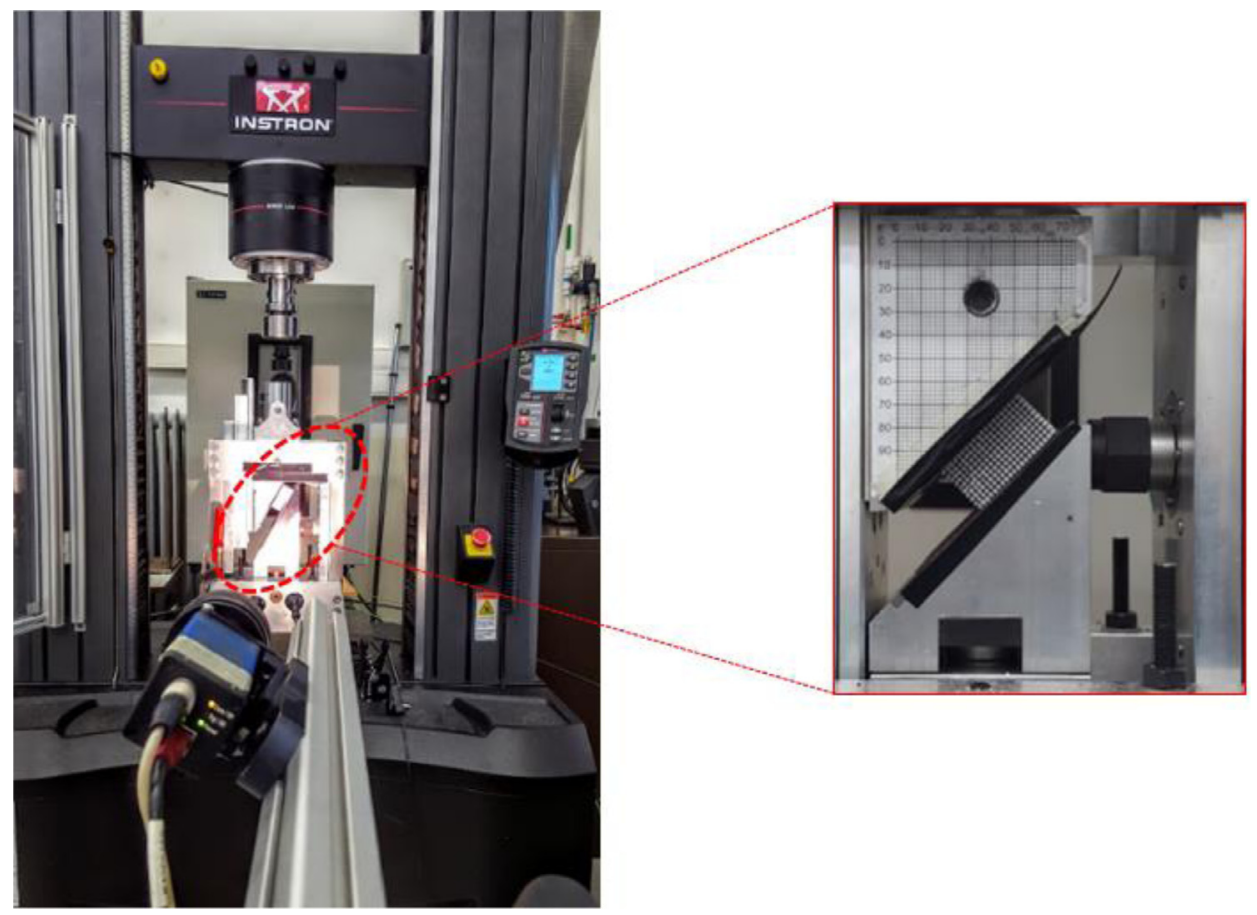

Fig. 8. Experimental setup with Instron machine and LIMESS system. 


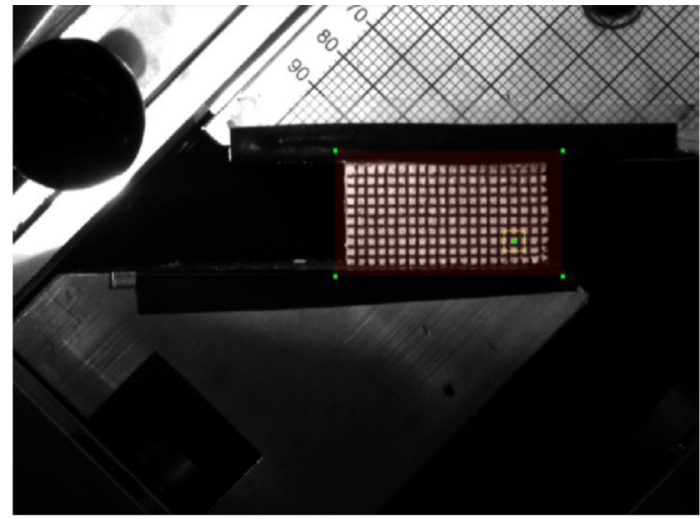

(a)

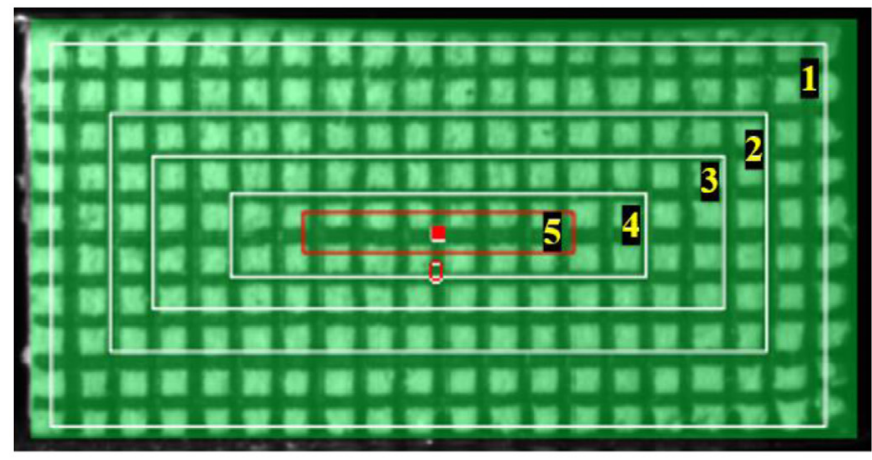

(b)

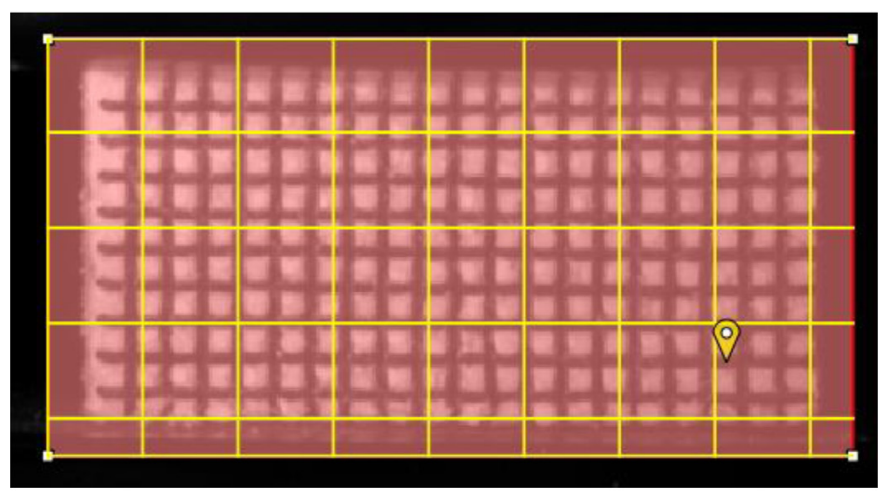

(c)

Fig. 9. (a) Strain processing from VIC-2D software; (b) The five inspection areas chosen from the reference image; (c) The subset size and start point used in the process.

$\mathrm{Y}$-axis. The vertical force sensor, which is located between the bottom wedge and the bottom frame as shown in Fig. 1, measures the corresponding vertical force. Rotation of the bottom wedge is restricted by the horizontal force sensor which is attached to the side frame of the test rig, and which measures the corresponding horizontal force. The compression and shear forces applied to the EPS foam can then be obtained indirectly from the two Kistler force sensors. Fig. 4 illustrates how the compression and shear forces are calculated from these:

Depending on the test wedge angle, the shear and compression forces are obtained directly via:

$F_{S}=F_{V} \sin \theta-F_{H} \cos \theta$,

$F_{C}=F_{H} \sin \theta+F_{V} \cos \theta$, where $F_{S}$ and $F_{C}$ are the shear and compression forces on the foam material and $F_{V}$ and $F_{H}$ are the vertical and horizontal forces recorded by the Kistler force sensors. $\theta$ is the angle between the vertical direction and the normal direction of the contact surface.

\subsection{Strain measurement}

A commercial LIMESS optical strain field measuring system, shown in Fig. 5, was used to measure the full field strain of the EPS foam samples during testing, from which the strains was obtained based on Digital Image Correlation (DIC) [29]. Pictures of the foam sample during the test were taken during each test at low sampling rates. 2D image correlation software, VIC-2D [30], was used subsequently to obtain the strain by analysing the pictures. Two different patterns were evaluated on the EPS foam surface as the image tracking pattern to obtain the strain, as shown in Fig. 6. The conventional spray paint speckle pattern tends to have low contrast due to the roughness of the foam surface and poor illumination conditions during the experiment. In addition, debris in the form of EPS beads was also observed separating from the foam surface during the tests. All these made it difficult to track the deformation of the foam continuously. Additionally, a regular grid pattern marked on the sample surface by a CNC machine with a pre-set programme, shown in Fig. 7, was used in separate trial experiments. It transpired that the grid pattern has a much higher robustness and identifiable pattern units for the VIC-2D imagine correlation software, which made it possible to track full-field deformations and to deduce strains in the foam samples. Thus, the regular grid pattern was adopted for all experiments, from which the evolution of compressive strain and shear strain in the EPS foam during the tests could be obtained (Fig. 8).

\section{Testing methods and results}

\subsection{Material and specimens}

In our study, four different densities of EPS foam material were used for the tests, namely $43,64,80,120 \mathrm{~kg} / \mathrm{m}^{3}$ respectively. The foam material was cut into blocks with nominal dimensions of $50 \times 50 \times 25 \mathrm{~mm}^{3}$ and loaded in the direction of the $25 \mathrm{~mm}$ dimension.

\subsection{Experimental design}

The test rig was fixed under the crosshead of the Instron machine; a compression mode with a quasi-static loading speed of $10 \mathrm{~mm} / \mathrm{min}$ was used. The LIMESS strain field measuring system was set up to focus on the deformation of the foam. Due to the slow deformation of the foam material under quasi-static loading, a low sampling rate was adopted, in which the camera was programmed to take one picture every two seconds. The resolution of the images is $1043 \times 1392$ pixels.

\subsection{Effect of the size of the inspection area on the strain measurement}

The level of strain within the EPS foam was obtained by first selecting a rectangular inspection area from the reference image taken in the absence of any load being applied. The displacement analyses of the deformed images are made with respect to this reference image based on the correlation analysis algorithm, after which the average strain within this area could be extracted. To study the effect of the different sizes inspection areas on the value of the strain, five different sizes (with the dimensions $45 \times 20 \mathrm{~mm}^{2}$ for size $1 ; 40 \times 15 \mathrm{~mm}^{2}$ for size $2 ; 35 \times 10 \mathrm{~mm}^{2}$ for size $3 ; 25 \times 5 \mathrm{~mm}^{2}$ for size $4 ; 18 \times 2.5 \mathrm{~mm}^{2}$ for size 5 ; cf. Fig. 9 (b)) were chosen from the reference image of the quasi-static test on the $80 \mathrm{~kg} / \mathrm{m}^{3}$ EPS foam. The corresponding strains obtained from the five areas were then compared.

The VIC-2D software calculates the engineering strain of the foam based on the displacement of the deformed images compared with the reference image by using the correlation algorithm. A subset size of 41 


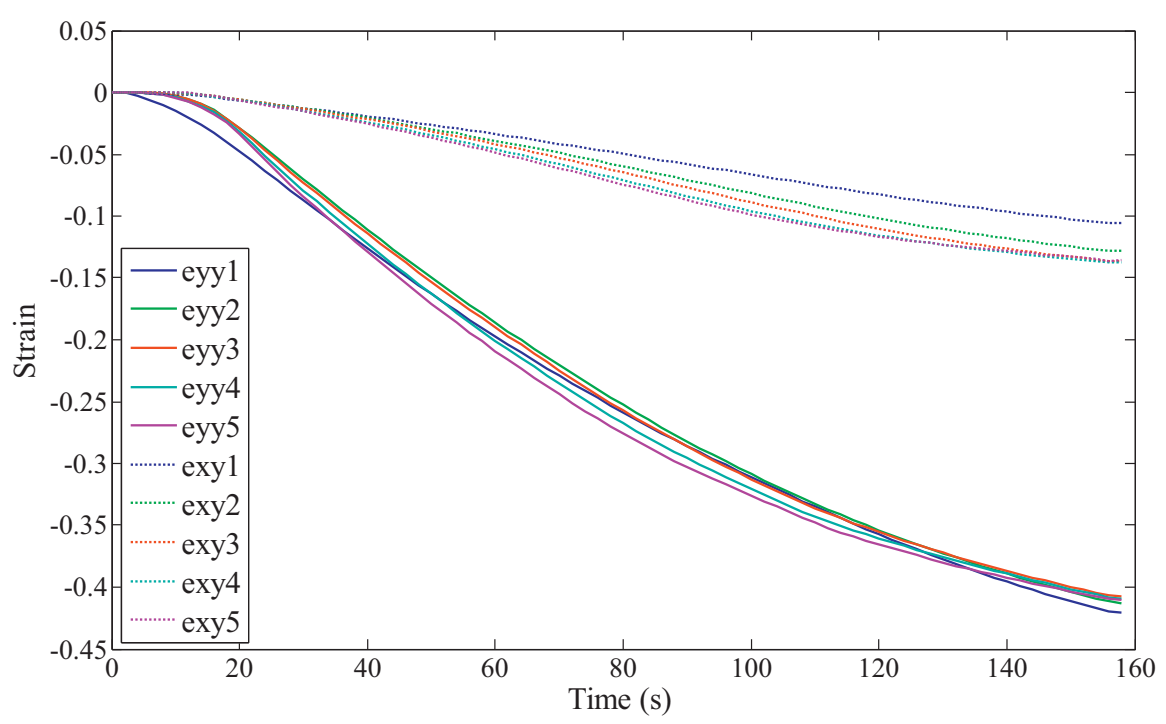

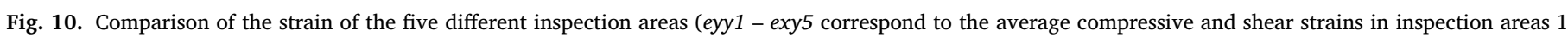
to 5$)$.

Table 1

Comparison of compressive and shear stress at yield for different densities foam.

\begin{tabular}{lllll}
\hline Foam density $\left(\mathrm{kg} / \mathrm{m}^{3}\right)$ & 43 & 64 & 80 & 120 \\
Compressive stress at yield (MPa) & 0.22 & 0.32 & 0.47 & 0.92 \\
Shear stress at yield $(\mathrm{MPa})$ & 0.10 & 0.13 & 0.16 & 0.27 \\
\hline
\end{tabular}

and step size of 2 were used during the process, a start point, where the correlation is started, was selected in the right bottom area of the foam sample (see at the yellow balloon symbol at Fig. 9(c)), as the amount of motion is relatively smaller in this area during the test, which can reduce the amount of work required to select an initial guess for the VIC-2D software. The average compressive and shear strain of this area, eyy and exy, were then extracted from the inspection rectangle and compared.

As shown from this figure, the compressive strain, eyy, doesn't change appreciably with the size of the inspection area. However, the shear strain, exy, changes slightly more for the different size inspection areas but becomes stable from inspection areas size 2 and smaller, as indicated in Fig. 10. This could be due to the fact that the foam edges were constrained by the wedges and shear deformation was restrained at these edges. Shear strain tends to be slightly smaller in the size 1 inspection area, as it is calculated as an average over a larger area. However, this effect becomes sufficiently small that it can be ignored when the inspection size reduces, as evident when comparing the difference of shear strain from size 2 to size 5 . Thus, in order to have a reliable comparison of the strain for different density foams, it is inspection rectangle size 4 that was always chosen to estimate the average strains.

Fig. 11 shows the distribution of the compressive and shear strains exx and exy along the thickness of a $80 \mathrm{~kg} / \mathrm{m}^{3}$ foam sample. The corresponding strains at the four selected points were calculated and compared in Fig. 11(b) and (c); this shows that exx is very small compared with the corresponding exy for all the four points. The compressive strain exx for all points are approximately zero with some variations along the thickness of the foam sample. All of them have values that are far below the corresponding shear strain, exy, which clearly demonstrates the ability of the bottom wedge to restrain the elongation of the bottom area of the foam sample.

\subsection{Experimental results}

Four different densities of EPS foam were used in the experiments, from a lowest density of $43 \mathrm{~kg} / \mathrm{m}^{3}$ to the highest density of $120 \mathrm{~kg} / \mathrm{m}^{3}$.
The forces from the two Kistler load cells were recorded at the same sampling rate of the LIMESS strain field measuring system. The compressive and shear stress and strain could be obtained from both the Kistler load cells and LIMESS system.

Fig. 12 shows the evolution of deformation and strain of the $80 \mathrm{~kg} / \mathrm{m}^{3}$ EPS foam under quasi-static combined compression and shear every $40 \mathrm{~s}$ until $160 \mathrm{~s}$, after which time the test was stopped. The compression and shear strain images from the VIC-2D software at the corresponding instances are provided.

Fig. 13 presents the compressive and shear strains of different density EPS foam changing with time. During the tests, the movement of the crosshead is displacement controlled by the machine, which means the displacement of the crosshead is the same for different density foams during same duration. As the dimensions of all foam samples are the same, thereby the compressive and shear strains of the foam samples should be identical, irrespective of the foam density. From Fig. 13 we can find that the compressive strains of the different density foam samples are quite stable, while the shear strains vary slightly, which is most likely due to the different extent of small micro cracks initiating and evolving during the tests due to shear deformation, as there is a different extent of macro cracks being observed for different density foams at the end of tests, especially for the $120 \mathrm{~kg} / \mathrm{m}^{3}$ foam, which tends to be more brittle compared with the other density foams: a large diagonal crack through the foam was observed at the end of the test, and the shear strain is higher compared with 64 and $80 \mathrm{~kg} / \mathrm{m}^{3}$ foam, as indicated from Fig. 13 .

The stress and strain curves for different density foam samples are presented below in Fig. 14. Note that the stresses in the curves were obtained from the average forces recorded by the load cells; the strains, on the other hand, were obtained directly from observations of inspection area 4, as shown in Fig. 9(b). Since the foam samples were not deformed uniformly, the strains in inspection area 1 were influenced by edge effects, and consequently, we have chosen the inner inspection area, area 4 , as having relatively uniform deformations, with small measurement errors and similar accuracy for all test samples and conditions.

As shown in Fig. 14(a), the compressive stress-strain curves for different densities of EPS foam under combined compression and shear loading are the typical stress and strain curves of cellular solids, with a linear elastic phase at the beginning being followed by a relatively large stress plateau phase, after which, the stress finally increases quickly once densification occurs. However, it is noteworthy that the shear stress strain curves also follow this similar transition, in which a large shear stress plateau is found and this is followed by shear yielding of the foam sam- 
(a)

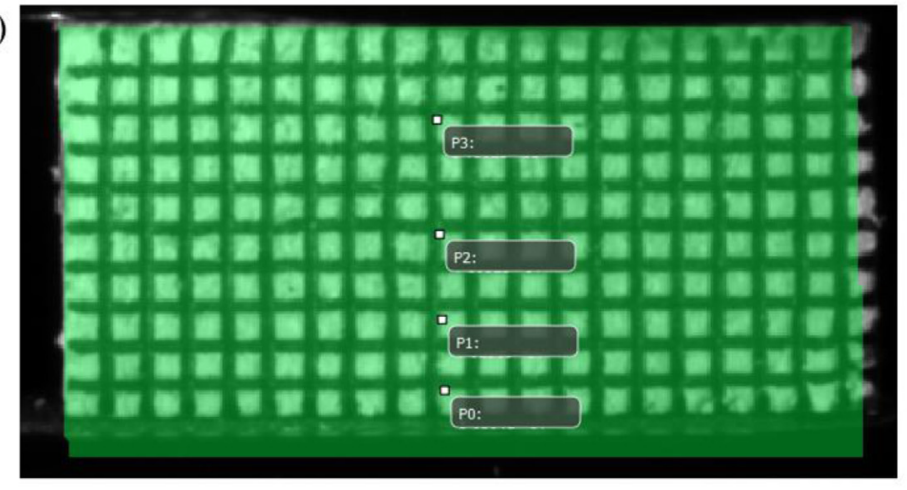

(b)
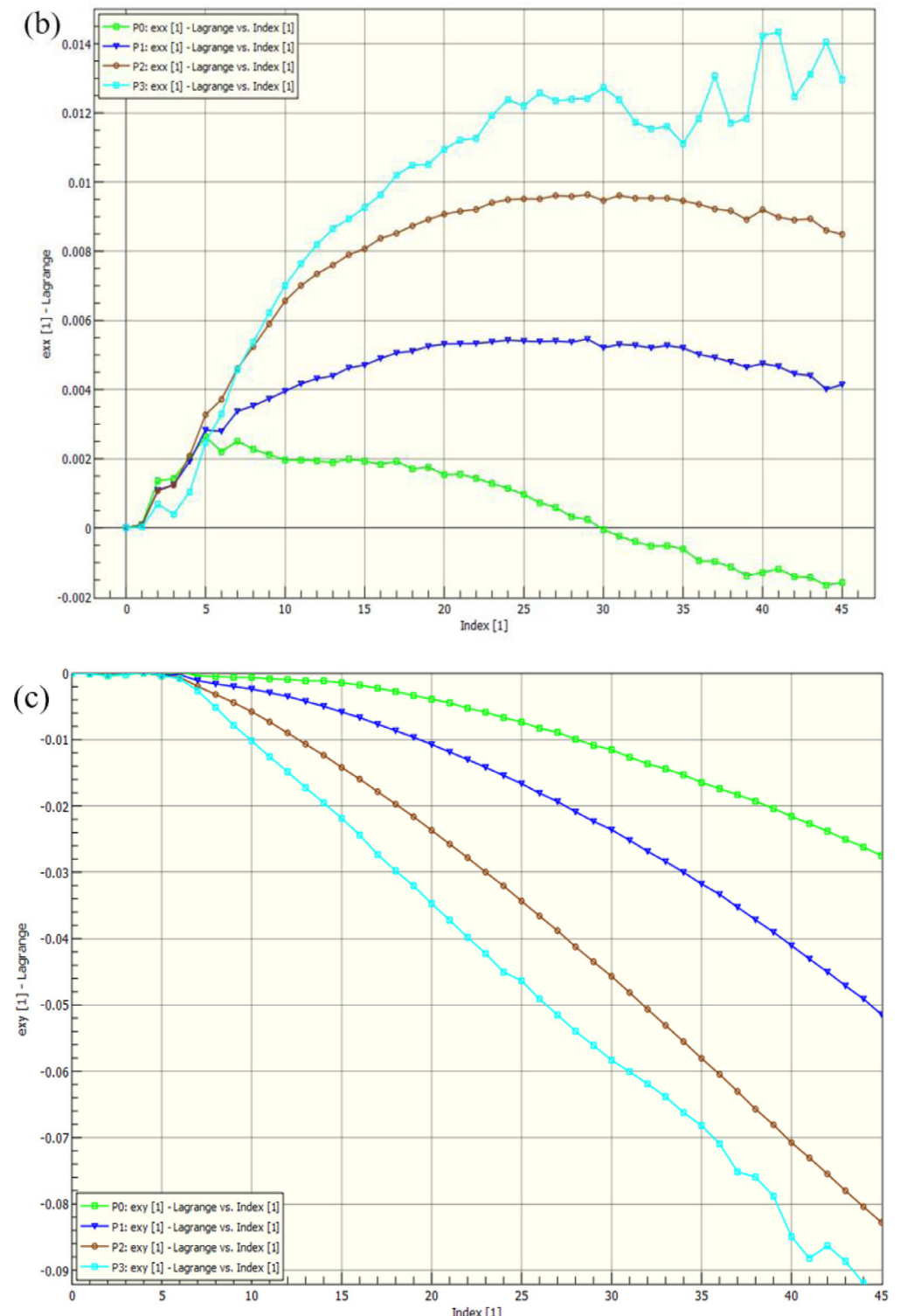

Fig. 11. Distribution of the exx along the thickness of the sample: (a) The four points along the thickness of the foam sample; (b) The change of the exx with the images index processed by VIC-2D (proportional to time); (c) The change of the exy with the images index processed by VIC-2D.

ples. In our experimental design, the compressive and shear stress were obtained independently, thus the shear stress was not influenced by the compressive stress, however, the significant increase of the shear stress during the densification phase occurs due to the significant increase of foam density resulting from high levels of compressive strain. The slightly waviness of these curves is believed to be due to small cracks occurring inside the foam during the shear stress plateau phase, as some of the foam samples developed into a visible crack through the thickness of the whole sample shortly before either failure or stopping a test. 


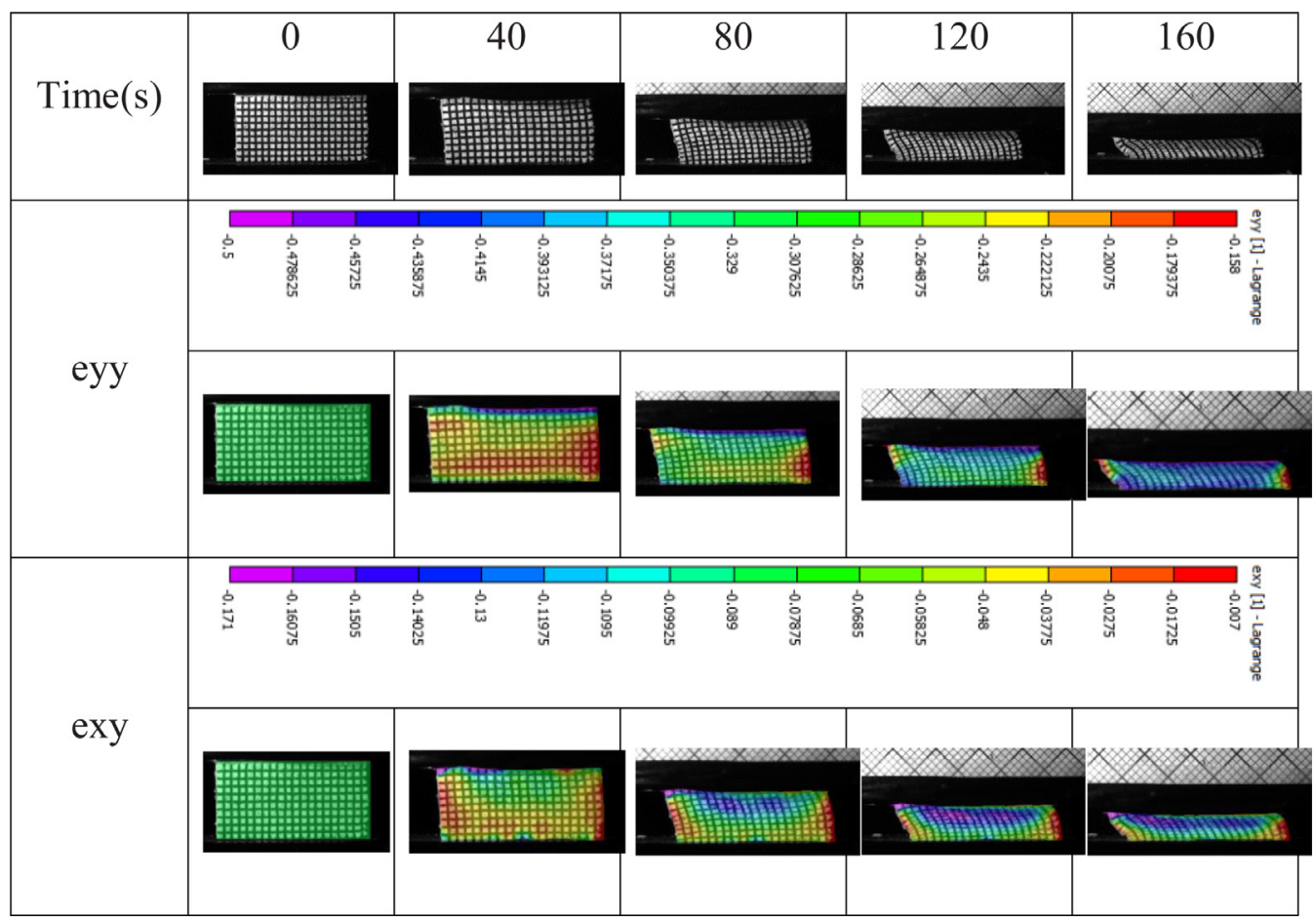

Fig. 12. The actual deformation, compression strain (eyy) and shear strain (exy) of $80 \mathrm{~kg} / \mathrm{m}^{3}$ foam under quasi-static combined compression and shear (Note: the thickness of the foam block reduces by $4.7 \mathrm{~mm}$ every $40 \mathrm{~s}$ given by the compression speed at $10 \mathrm{~mm} / \mathrm{min}$ with $45^{\circ}$ loading angle).

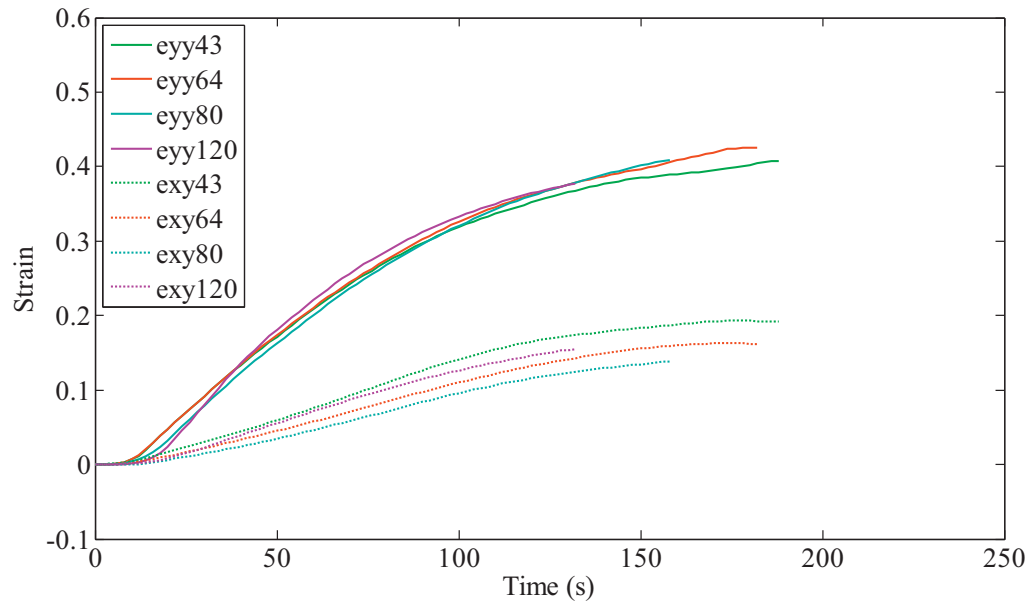

Fig. 13. compressive and shear strain of different densities EPS foam.

Table 2

Comparison of compressive stress at yield for different densities foam under $45^{\circ}$ compression wedge and pure compression.

\begin{tabular}{lllll}
\hline Foam density $\left(\mathrm{kg} / \mathrm{m}^{3}\right)$ & 43 & 64 & 80 & 120 \\
Compressive stress at yield under $45^{\circ}$ compression wedge loading (MPa) & 0.22 & 0.32 & 0.47 & 0.92 \\
Compressive stress at yield under pure compression (MPa) & 0.33 & 0.53 & 0.70 & 1.26 \\
\hline
\end{tabular}

The shear stress at yield is also much lower than the compressive stress at yield for the same density foam, as listed in Table 1 below, though both of them increase directly with foam density.

Pure compression tests on EPS foam for these four density foams were additionally done according to the ASTM D 1621-00 standard test method. Fig. 15 shows the compressive stress strain curves for the four densities of foam.

Table 2 compares the compressive stress at yield of the foam using the $45^{\circ}$ compression wedge and pure compression respectively. As can be seen, the stress at yield under the $45^{\circ}$ compression wedge is lower when compared with that for pure compression. This indicates that shear deformation weakens the foam, resulting in a reduced compressive stress at yield of the EPS foam during combined compression and shear loading. It is also noteworthy to find that the densification strain for compressive stress under combined compression and shear loading is around 0.3 lower when compared with the pure compression test (consider, for example, the $80 \mathrm{~kg} / \mathrm{m}^{3}$ foam: its compressive densification strain under combined compression and shear loading is around 


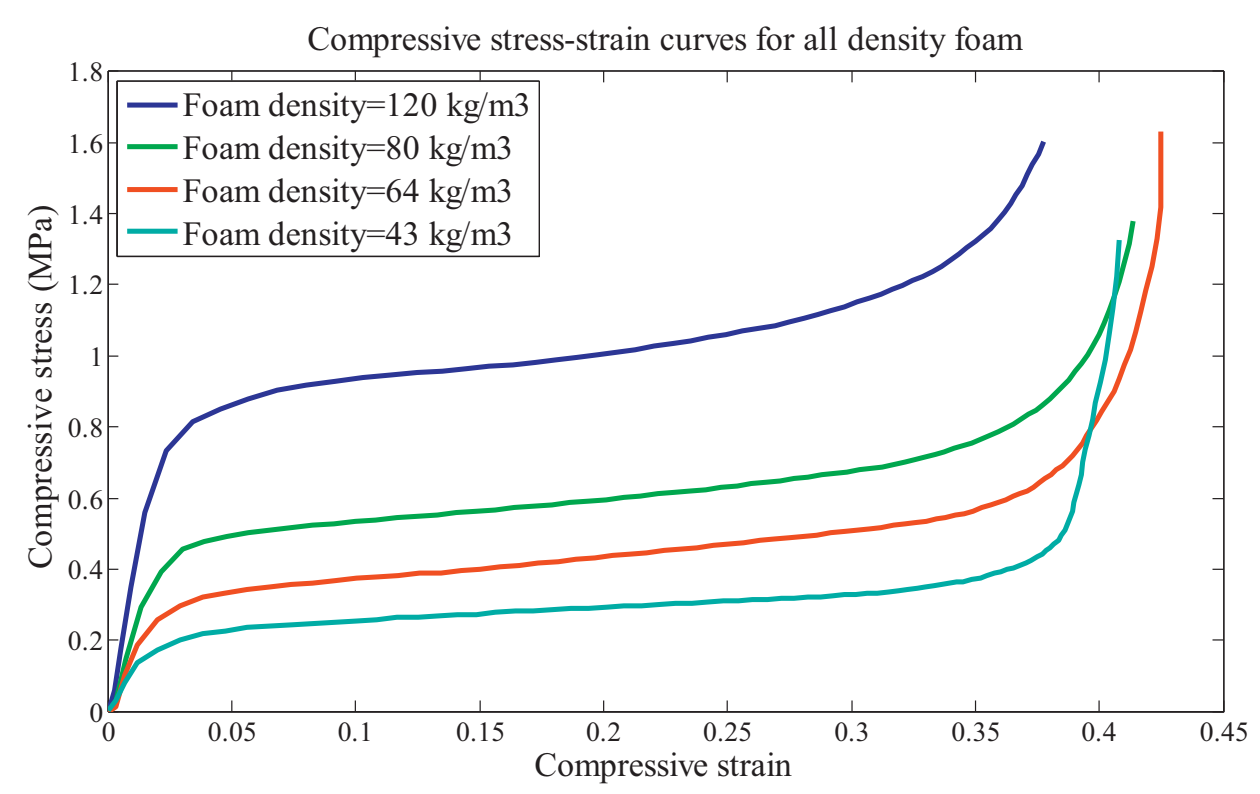

(a)

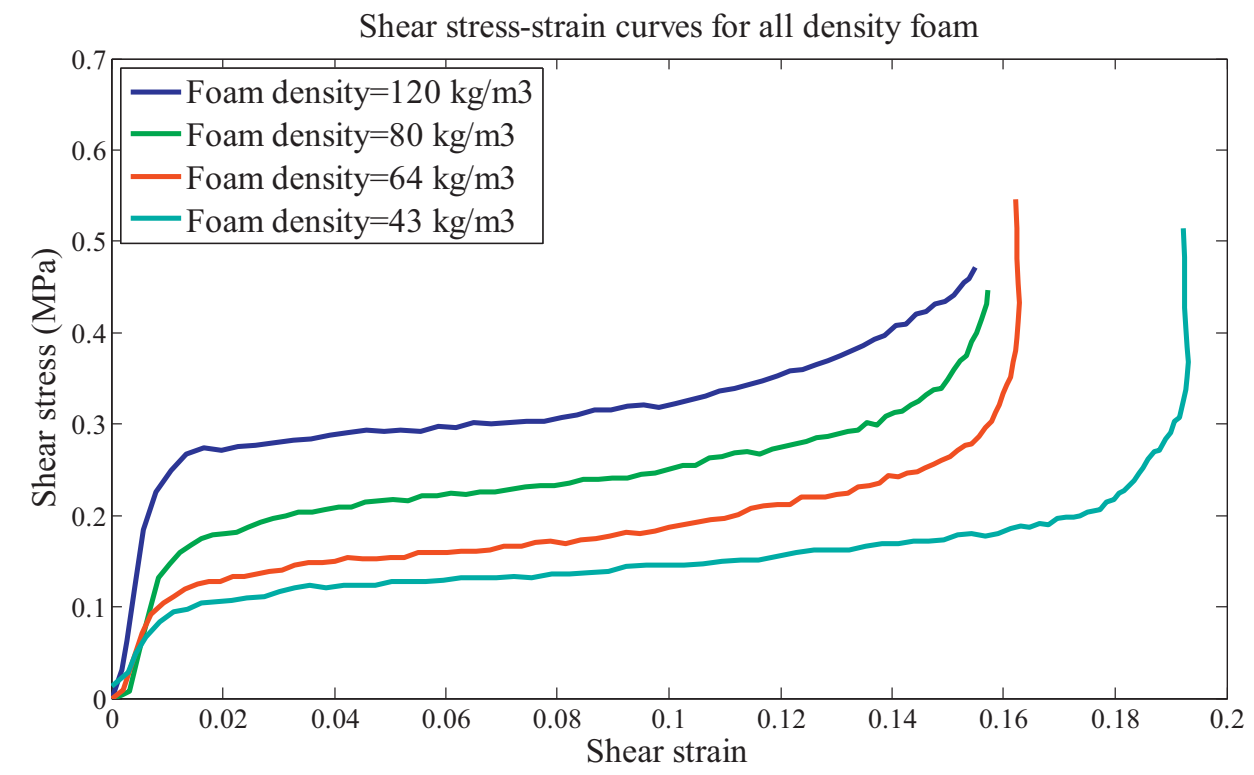

(b)

Fig. 14. (a) compressive stress strain curve; (b) shear stress strain curve of EPS foam under quasi-static loading at $45^{\circ}$ loading angle.

0.3 , while under pure compression it is around 0.6 ). We propose a possible explanation here, however, further investigation of the deformed cellular structure by SEM or micro CT is needed to confirm this assumption: The foam densification occurs when all the foam cellular structures collapses and densifies. Under pure compression tests, the collapse of the foam cellular structures is solely due to the compressive deformation, however, for foams tested under combined compression and shear loading, both the compression loading and shear loading contribute to the deformation, collapse and densification of the foam cellular structures at the same time, which results in the lower compressive densification strain of EPS foam when compared with that under pure compression.

\section{Conclusions}

In this paper, we developed a test method and apparatus to investigate the mechanical behaviour of EPS foam material under the action of combined compression and shear loading. The apparatus was assembled and integrated with a universal INSTRON test machine to perform the experimental tests.

The strain of the EPS foam was measured successfully by the DIC strain field measuring system. A special regular grid was used on the foam surface as the tracking pattern for DIC strain measurement, which we investigated during the experiments and which was found to work very well in this application.

The compressive and shear stress strain curves of EPS foam under combined compression and shear loading were obtained. It was found that the shear stress at yield is lower when compared with the compressive stress at yield. The compressive stress at yield under combined compression and shear loading was also compared with that under pure compression: the result shows that under combined compression and shear loading, the compressive stress at yield is lower than that under pure compression, since the shear deformation tends to weaken the com- 
Compressive stress-strain curves for all density foam under pure compression

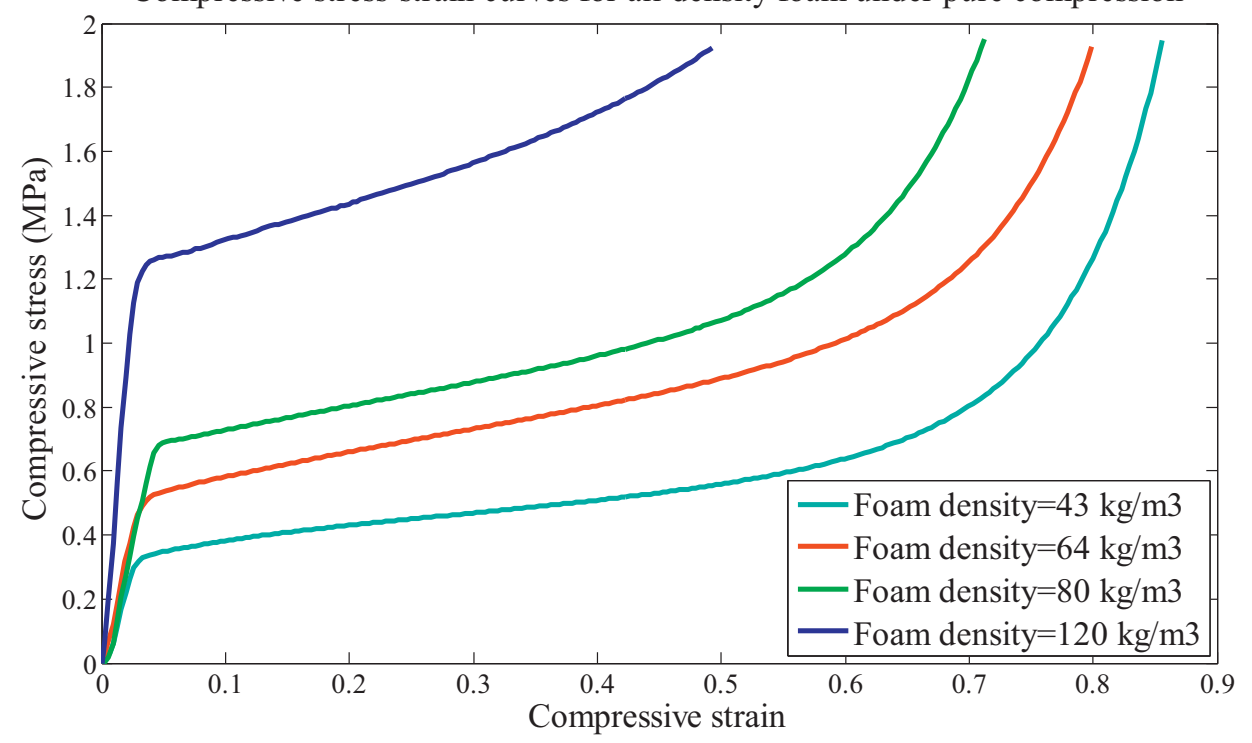

Fig. 15. Compressive stress-strain curves of EPS foam under pure compression.

pressive yielding strength of the EPS foam. This difference was found to be as much as $40 \%$, depending on the density of the foam sample.

\section{Acknowledgements}

This work was sponsored by the European Union's Horizon 2020 research and innovation programme under the Marie Skłodowska-Curie grant agreement (No. 642662). CL would like to thank the CMG group from KU Leuven for hosting his secondment study, where the work reported in this paper was carried out. The authors also thank technicians from KU Leuven's MTM Department, both Mr. Marc Peeters and Mr. Joop van Deursen for the design, manufacture of the test rig and discussion of the experimental results.

\section{References}

[1] Ozturk UE, Anlas G. Finite element analysis of expanded polystyrene foam under multiple compressive loading and unloading. Mater Des 2011;32(2):773-80.

[2] Singh SP, Burgess G, Singh J. Performance comparison of thermal insulated packaging boxes, bags and refrigerants for single-parcel shipments. Packag Technol Sci 2008;21(1):25-35.

[3] Fernando PLN, Jayasinghe MTR, Jayasinghe C. Structural feasibility of Expanded Polystyrene (EPS) based lightweight concrete sandwich wall panels. Constr Build Mater 2017;139:45-51.

[4] Babu DS, Babu KG, Wee TH. Properties of lightweight expanded polystyrene aggregate concretes containing fly ash. Cem Concr Res 2005;35(6):1218-23.

[5] Mohamed G, Hegazy R, Mohamed M. An investigation on the mechanical behavior of expanded polystyrene (EPS) geofoam under different loading conditions. Int J Plast Technol 2017;21(1):123-9.

[6] Ossa A, Romo MP. Micro- and macro-mechanical study of compressive behavior of expanded polystyrene geofoam. Geosynth Int 2009:327-38.

[7] Forero Rueda MA, Gilchrist MD. Comparative multibody dynamics analysis of falls from playground climbing frames. Forensic Sci Int 2009;191(1-3):52-7.

[8] Di Landro L, Sala G, Olivieri D. Deformation mechanisms and energy absorption of polystyrene foams for protective helmets. Polym Test 2002;21(2):217-28.

[9] Cui L, Forero Rueda MA, Gilchrist MD. Optimisation of energy absorbing liner for equestrian helmets. Part II: Functionally graded foam liner. Mater Des 2009;30(9):3414-19.

[10] Forero Rueda MA, Cui L, Gilchrist MD. Optimisation of energy absorbing liner for equestrian helmets. Part I: Layered foam liner. Mater Des 2009;30(9):3405-13.

[11] Gilchrist MD, O'Donoghue D, Horgan T. A two dimensional analysis of the biomechanics of frontal and occipital head impact injuries. Int J Crashworthiness 2001;6(2):253-62.
[12] Forero Rueda MA, Halley WL, Gilchrist MD. Fall and injury incidenced rates of jockeys while racing in Ireland, France and Britain. Injury 2010;41:533-9.

[13] Geofoam. Available from: https://en.wikipedia.org/wiki/Geofoam.

[14] Chen W, Hao H, Hughes D, Shi Y, Cui J, Li Z-X. Static and dynamic mechanical properties of expanded polystyrene. Mater Des 2015;69:170-80.

[15] Krundaeva A, De Bruyne G, Gagliardi F, Van Paepegem W. Dynamic compressive strength and crushing properties of expanded polystyrene foam for different strain rates and different temperatures. Polym Test 2016;55:61-8.

[16] Ashby MF. The mechanical properties of cellular solids. Metallurg Trans A 1983;14(9):1755-69.

[17] Chen YM, Das R, Battley M. Effects of cell size and cell wall thickness variations on the stiffness of closed-cell foams. Int J Solids Struct 2015;52:150-64.

[18] Mihlayanlar E, Dilmac S, Guner A. Analysis of the effect of production process parameters and density of expanded polystyrene insulation boards on mechanical properties and thermal conductivity. Mater Des 2008;29(2):344-52.

[19] Song B, Chen WNW, Dou SB, Winfree NA, Kang JH. Strain-rate effects on elastic and early cell-collapse responses of a polystyrene foam. Int J Impact Eng 2005;31(5):509-21.

[20] Ouellet S, Cronin D, Worswick M. Compressive response of polymeric foams under quasi-static, medium and high strain rate conditions. Polym Test 2006;25(6):731-43.

[21] Koohbor B, Kidane A, Lu WY, Sutton MA. Investigation of the dynamic stress-strain response of compressible polymeric foam using a non-parametric analysis. Int J Impact Eng 2016;91:170-82.

[22] Hou B, Ono A, Abdennadher S, Pattofatto S, Li YL, Zhao H. Impact behavior of honeycombs under combined shear-compression. Part I: Experiments. Int J Solids Struct 2011;48(5):687-97.

[23] Hou B, Pattofatto S, Li YL, Zhao H. Impact behavior of honeycombs under combined shear-compression. Part II: Analysis. Int J Solids Struct 2011;48(5):698-705.

[24] Tounsi R, Zouari B, Chaari F, Markiewicz E, Haugou G, Dammak F. Reduced numerical model to investigate the dynamic behaviour of honeycombs under mixed shear-compression loading. Thin-Walled Struct. 2013;73:290-301.

[25] Dorogoy A, Rittel D. Dynamic large strain characterization of tantalum using shearcompression and shear-tension testing. Mech Mater 2017;112:143-53.

[26] Vogler TJ, Hsu SY, Kyriakides S. Composite failure under combined compression and shear. Int J Solids Struct 2000;37(12):1765-91.

[27] Vogler TJ, Kyriakides S. Inelastic behavior of an AS4/PEEK composite under combined transverse compression and shear. Part I: Experiments. Int J Plast 1999;15(8):783-806.

[28] Mosleh Y, Van den Bosche K, Depreitere B, Vander Sloten J, Verpoest I, Ivens J. Effect of polymer foam anisotropy on energy absorption during combined shearcompression loading. J Cell Plast 2017:0021955X17720156.

[29] LIMESS. Available from: https://www.limess.com/en/products/q400-digital-imagecorrelation.

[30] VIC-2D. Available from: http://correlatedsolutions.com/vic-2d/. 